\title{
Further developments in the redrying and storage of prechilled beechnuts (Fagus sylvatica L.): effect of seed moisture content and prechilling duration
}

\author{
Claudine Muller ${ }^{\mathrm{a}^{*}}$, Elyane Laroppe ${ }^{\mathrm{a}}$, Marc Bonnet-Masimbert ${ }^{\mathrm{b}}$ \\ ${ }^{a}$ Inra Centre de Nancy 54280 Champenoux, France \\ ${ }^{\mathrm{b}}$ Inra Centre d'Orléans 45160 Ardon, France
}

(Received 11 February 1998; accepted July 1998)

\begin{abstract}
Techniques for breaking dormancy of beechnuts (Fagus sylvatica) have been greatly improved over the last 20 years. A major improvement has been the introduction of a new procedure involving prechilling after rehydration of the seeds to a precise moisture content (m.c.) (28-30\%). This allows long-term storage of non-dormant beechnuts. This study aimed to: i) optimize prechilling conditions by prechilling seeds at a range of moisture contents $(28-34 \%)$ for different durations $(\mathrm{X}$ to $\mathrm{X}+6$, where $\mathrm{X}$ is the duration necessary to obtain the germination of $10 \%$ of the viable seeds under stratification in a wet medium at $3{ }^{\circ} \mathrm{C}$ ); ii) follow changes in the germination ability of prechilled seeds during 3 years of storage. The germination capacity of beechnuts was tested just after prechilling, after prechilling and drying down to $8 \%$, and after prechilling, then drying and storage. The best maintenance of the germination percentage during storage was obtained when seeds were prechilled at $30 \%$ m.c. for X+2 weeks. A damaging effect of drying was observed when the moisture content of the seeds during prechilling was high $(34 \%)$ and the duration long $(X+6)$. When prechilling was applied after storage the best results were obtained at $32 \%$ m.c. (@ Inra/Elsevier, Paris.)
\end{abstract}

Fagus sylvatica / beechnut / seed / dormancy / storage

Résumé - Progrès dans la conservation des faines (Fagus sylvatica L.) prétraitées : influence de la teneur en eau des faines et de la durée de prétraitement. Les techniques de levée de dormance des faines (Fagus sylvatica) ont été grandement améliorées au cours des vingt dernières années. Un progrès majeur a résulté de l'introduction d'une technique de prétraitement après réhydratation des semences à un niveau de teneur en eau (TE) contrôlé (28-30\%). De plus, ceci a ouvert la voie à la conservation à long terme des faines dans un état non-dormant. Notre étude visait à : i) optimiser les conditions du prétraitement : TE des faines variant entre 28 et $34 \%$ et durées variant entre $\mathrm{X}$ et $\mathrm{X}+6$ (où $\mathrm{X}$ représente le nombre de semaines permettant la germination de $10 \%$ des faines viables, en condition de stratification dans un milieu humide à $3{ }^{\circ} \mathrm{C}$ ) ; ii) suivre pendant trois années de conservation l'évolution de la faculté germinative des faines ainsi prétraitées. Des tests de germination ont été effectués juste après le prétraitement, après prétraitement et séchage à TE $8 \%$, et après prétraitement, séchage et conservation.

Le meilleur maintien de la faculté germinative est obtenu à la suite d'un prétraitement à TE $30 \%$ pendant $\mathrm{X}+2$ semaines. Le séchage occasionne une baisse de faculté germinative lorsque le prétraitement a été effectué à TE $34 \%$ et pour la durée la plus longue (X+6). Lorsque le prétraitement est appliqué après conservation, les meilleurs résultats sont obtenus à TE $32 \%$. (C) Inra/Elsevier, Paris.)

Fagus sylvatica / faines / semence / dormance / conservation

\footnotetext{
* Correspondence and reprints cmuller@nancy.inra.fr
} 


\section{INTRODUCTION}

The European beech (Fagus sylvatica L.) is an important timber species often used in forestry. Beechnuts, like many other forest seeds, possess embryo dormancy which responds to cold. The dormancy can be particularly deep because it may require 4 to 20 weeks of prechilling at a temperature of 1 to $5^{\circ} \mathrm{C}$ before it is broken $[6,12,18,23]$. This dormancy can vary greatly from year to year, from one seedlot to another and, even within a seedlot, from one seed to another.

Traditionally, beechnuts are prechilled at $3{ }^{\circ} \mathrm{C}$ in a moist medium (cold stratification) but the seeds will also germinate at this temperature as soon as dormancy is broken [16]. This premature germination during chilling creates problems for sowing. Therefore, Suszka and Zieta [20] proposed a modification to the traditional treatment by interrupting the pretreatment when $10 \%$ of nuts have germinated. This duration, expressed in weeks, is designated as ' $\mathrm{X}$ '. It is clear that after $\mathrm{X}$ weeks of chilling, dormancy is not completely released and so seedling emergence is generally neither uniform nor complete. Moreover, since germination is considered an irreversible process, there is no way to dry the seed after prechilling without serious damage to seeds in the early stages of germination.

In 1975, to overcome the drawbacks of the classical cold stratification with a medium, a new procedure of prechilling, based on the control of seed moisture content (m.c.) without a medium was developed for beechnuts in Poland [17] and further elaborated in France [11, 12]. In this procedure seeds are moistened during prechilling to a m.c. of $28-30 \%$ and then maintained at $3{ }^{\circ} \mathrm{C}$ for 2 weeks longer (i.e. $\mathrm{X}+2$ weeks) than for classical stratification. This precise m.c. is enough for dormancy breaking to be achieved, but it does not allow seeds to germinate. As a consequence, seeds can be dried without damage after the prechilling which can be applied immediately after harvest, or after a period of storage and before sowing [10].

Since 1976 we have conducted many experiments and obtained very promising results for storing non-dormant beechnuts for up to 8 years $[11,12,14,22,23]$. In recent years the new methodology has been applied in France on a large scale by the 'Office National des Forêts' and by seed companies. In 1990 one of the largest French seed companies (Vilmorin, Angers) applied the procedure to 10 tons of beechnuts and achieved an average germination (among different seedlots) of 60-70\%. These nondormant beechnuts were successfully used over the next 18 months.

The purpose of this study was: i) to optimize prechilling conditions, with respect to both seed moisture content and the duration of chilling and ii) to follow changes in the germination of prechilled seeds for 3 years of storage in relation to these conditions.

In addition, we tested whether the same dormancy breakage conditions would be equally effective before or after storage, i.e. whether seeds were stored in a non-dormant or dormant state.

\section{MATERIALS AND METHODS}

\subsection{Seed material}

A Danish seedlot $(45 \mathrm{~kg})$, supplied by the Tree Improvement Station (Humlebaek) was used for the experiments. Upon arrival, in December 1993, seed m.c. was $21.6 \%$ and viability $77 \%$. The degree of dormancy (X) was determined in stratification just after arrival (before and after drying): 6 weeks were necessary to obtain $10 \%$ of germination at $3{ }^{\circ} \mathrm{C}$ for wet beechnuts and only 4 weeks for dried beechnuts.

\subsection{Prechilling, drying and storage conditions}

A part of the seedlot $(25 \mathrm{~kg})$ was prechilled just after arrival. The following m.c. and prechill durations were applied in a factorial design: $28,30,32$ and $34 \%$ m.c. and $X, X+2, X+4$ and $X+6$ weeks for the durations $(X=6$ weeks). The longest duration thus corresponds to 12 weeks of pretreatment. In this paper 'prechilling' will designate prechilling without medium in contrast to 'stratification' which designates a prechilling into a wet medium. After pretreatment this first lot was dried at room temperature to $7-8 \%$ m.c. and stored at $-7{ }^{\circ} \mathrm{C}$. The remainder $(20 \mathrm{~kg})$ of the seedlot was stored in a dormant state for 18 months at $7-8 \%$ m.c. and $-7{ }^{\circ} \mathrm{C}$; they were then prechilled at 30,32 and $34 \%$ m.c. for $\mathrm{X}+2, \mathrm{X}+4$, $\mathrm{X}+6$ and $\mathrm{X}+11$ weeks just before sowing.

\subsection{Germination tests}

Germination tests were performed on four replicates of 50 seeds (randomized block design), in darkness, in the laboratory on moist filter paper at $3^{\circ} / 20^{\circ} \mathrm{C}(16 \mathrm{~h}+8 \mathrm{~h})$. These alternating temperatures are generally used in our laboratory because they have shown a good correlation with germination in nursery conditions.

The results are expressed as germination percentage (GP) in the laboratory or seedling emergence percentage (SEP) in the nursery and mean germination time (MGT) 
(or coefficient of velocity) [9] calculated with the formula:

$$
\operatorname{MGT}=\left(n_{\mathrm{i}} \cdot t_{\mathrm{j}}\right) / N
$$

with $n_{\mathrm{i}}=$ number of germinated seeds after $t_{\mathrm{i}}$ days and $N=$ total germinated seeds at the end of the test.

The seeds were tested in the laboratory, after receiving the dormancy breaking treatments, before and after drying and after 1,2 and 3 years of storage.

After 18 months of storage, the germination and nursery emergence of seeds that had been prechilled before storage was compared with those pretreated after storage. In the nursery only the best treatments (according to the laboratory test after 1 year of storage) were sown, i.e. 30 and $32 \%$ m.c. during $\mathrm{X}+2$ and $\mathrm{X}+4$ weeks for seeds stored prechilled; 32 and $34 \%$ m.c. during $X+2$ weeks for seeds prechilled after storage.

\subsection{Statistical analyses}

Statistical differences for the number of germinated seeds per replicate and MGT were submitted to analysis of variance according to a two-way classification with interaction (procedure ANOVA, SAS). Bonferroni's multiple range test at 0.05 level of probability was applied to compare means of significant main factors or interaction.

\section{RESULTS}

The results will be presented in three stages: 1) just after prechilling, 2) after prechilling and drying and 3) after prechilling, drying and storage for 18 months in comparison to non-prechilled seeds also stored for 18 months.

\subsection{Effect of prechilling conditions: moisture content and duration}

Two series of tests were performed immediately after the arrival of the seeds in the laboratory.

\subsubsection{Results obtained just after prechilling}

The results are given in table $I$. Germination was significantly higher (average $80 \%$ ) at m.c. varying between 30 and $34 \%$ than at $28 \%$ m.c. where GP was $64.3 \%$. There was no significant difference between either average GP or MGT at 30, 32 and $34 \%$ m.c. For a short duration of prechill, such as $\mathrm{X}$ weeks, good germination was already obtained at 30 and $32 \%$ m.c. which suggests that breaking of dormancy starts earlier at 30 and $32 \%$ m.c. than at the other m.c. (28 and $34 \%$ ). However, X weeks (GP $61.2 \%$ on average) was not sufficient to completely break the dormancy. No significant difference was observed between $\mathrm{X}+2, \mathrm{X}+4$ and $\mathrm{X}+6$ weeks (GP around $80 \%$ ). For the speed of germination, the best results were obtained at 30-32\% m.c. and with the duration $\mathrm{X}+4$ weeks (individual treatment values not shown).

\subsubsection{Results obtained after drying}

The results are given in table II. The GP before and after drying, averaged for the factors 'duration' and 'moisture content', are also summarized in figure 1 . Immediately after drying, we generally observed a slight but significant decrease of GP: 5 to $10 \%$ on average, depending on the treatment - except for $\mathrm{X}$ weeks where there was a systematic increase (compare tables $I$ and $I$ ). The decrease was greater at the longest prechill duration, $\mathrm{X}+6$ weeks and the m.c. high ( $34 \%$ ). It is possible that some seeds were in the early stages of germination and

Table I. Effect of prechilling conditions, i.e. moisture content (m.c.) and duration on the germination percentage (GP) and the mean germination time (MGT) of beechnuts.

\begin{tabular}{lcccccc}
\hline m.c. (\%) & \multicolumn{3}{c}{ Duration of prechilling (weeks) } & Average & Average \\
\cline { 2 - 6 } & $\mathrm{X}$ & $\mathrm{X}+2$ & $\mathrm{X}+4$ & $\mathrm{X}+6$ & $\mathrm{GP}$ & MGT (days) \\
\hline 28 & $43.5 \mathrm{~b}$ & $71.5 \mathrm{a}$ & $76.0 \mathrm{a}$ & $66.5 \mathrm{a}$ & $64.3 \mathrm{~B}$ & $14.4 \mathrm{~B}$ \\
30 & $73.0 \mathrm{~b}$ & $85.0 \mathrm{a}$ & $88.0 \mathrm{a}$ & $81.0 \mathrm{ab}$ & $81.8 \mathrm{~A}$ & $9.9 \mathrm{~A}$ \\
32 & $69.5 \mathrm{~b}$ & $82.5 \mathrm{a}$ & $83.5 \mathrm{a}$ & $81.5 \mathrm{ab}$ & $79.3 \mathrm{~A}$ & $10.5 \mathrm{~A}$ \\
34 & $59.0 \mathrm{~b}$ & $81.0 \mathrm{a}$ & $86.0 \mathrm{a}$ & $92.0 \mathrm{a}$ & $79.5 \mathrm{~A}$ & $10.7 \mathrm{~A}$ \\
Average GP & $61.3 \mathrm{~b}$ & $80.0 \mathrm{a}$ & $83.4 \mathrm{a}$ & $80.3 \mathrm{a}$ & & \\
Average MGT(days) & $15.6 \mathrm{~d}$ & $11.8 \mathrm{c}$ & $8.5 \mathrm{a}$ & $9.6 \mathrm{~b}$ & & \\
\hline
\end{tabular}

Results for MGT are averaged across factors (no significant interaction). Laboratory tests were carried out immediately after the end of the prechilling. In the same row (small letters) or column (capital letters) values sharing the same letter are not significantly different. For germination, data are given in GP, but statistical comparisons have been operated on the number of germinated seeds per replicate. 
Table II. Effect of prechilling conditions, i.e. moisture content (m.c.) and duration on the germination percentage (GP) and the mean germination time (MGT) of beechnuts.

\begin{tabular}{|c|c|c|c|c|c|c|}
\hline \multirow[t]{2}{*}{ m.c. $(\%)$} & \multicolumn{4}{|c|}{ Duration of prechilling (weeks) } & \multirow{2}{*}{$\begin{array}{c}\text { Average } \\
\text { GP }\end{array}$} & \multirow{2}{*}{$\begin{array}{c}\text { Average } \\
\text { MGT (days) }\end{array}$} \\
\hline & $X$ & $X+2$ & $X+4$ & $X+6$ & & \\
\hline 30 & $78.5 \mathrm{a}$ & $78.0 \mathrm{a}$ & $78.5 \mathrm{a}$ & $72.0 \mathrm{a}$ & $76.7 \mathrm{~A}$ & $12.4 \mathrm{~A}$ \\
\hline 32 & $74.5 \mathrm{a}$ & $79.5 \mathrm{a}$ & $75.5 \mathrm{a}$ & $64.5 \mathrm{a}$ & $73.5 \mathrm{~A}$ & $13.3 \mathrm{AB}$ \\
\hline 34 & $75.5 \mathrm{a}$ & $77.5 \mathrm{a}$ & $75.5 \mathrm{a}$ & $51.5 b$ & $70.0 \mathrm{~A}$ & $13.7 \mathrm{~B}$ \\
\hline
\end{tabular}

Results for MGT are averaged across factors (no significant interaction). Laboratory tests were carried out at the end of the prechilling and after drying. In the same row (smail letters) or column (capital letters) values sharing the same letter are not significantly different. For germination, data are given in GP, but statistical comparisons have been operated on the number of germinated seeds per replicate.

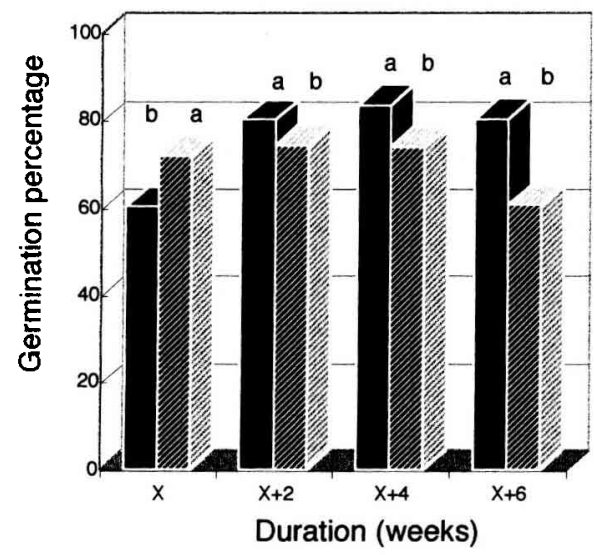

that the higher the m.c., the stronger the negative effect of drying.

After drying (table II) there was no effect of prechill duration in the range of $\mathrm{X}$ to $\mathrm{X}+4$ weeks whatever the moisture content. The best values for GP and MGT were always obtained in the range of 30-32\% (even $34 \%$ ) for the m.c., and $X, X+2$ and $X+4$ for the duration: GP varied between 74.5 and $79.5 \%$ and MGT was around 12 days (individual treatment values not shown).

\subsection{Storage for 18 months: comparison of seeds prechilled before storage and seeds prechilled after storage}

\subsubsection{Laboratory tests}

With regard to the GP of seeds prechilled before storage (table III), the best results were obtained at 30 and 32
$\%$ m.c. for $\mathrm{X}+2$ and $\mathrm{X}+4$ weeks. GP was significantly lower at $28 \%$ m.c. whatever the duration. At $34 \%$ m.c., GP decreased by $48 \%$ at the longest duration of prechilling $(\mathrm{X}+6)$. For seeds pretreated after storage (table V), the highest Gps were obtained at a moisture content slightly higher than for seeds prechilled before storage i.e. 32 and $34 \%$ m.c. The duration $X+2$ seems to be sufficient but $\mathrm{X}+4$ weeks and even longer periods can be used without any significant decrease in germination as opposed to what we observed for prechilling before storage.

In case of the MGT (tables $I V, V I$ ), the longer the pretreatment the faster the germination. MGT was particularly low for seeds prechilled after storage, most probably because they were sown moist (30-34 \% m.c.) as opposed to seeds prechilled before storage which were sown at their m.c. in storage, i.e. $8 \%$ m.c. 
Table III. Prechilling and drying applied before storage. Germination percentage (GP) at $3 \% 20{ }^{\circ} \mathrm{C}$ after 18 months of storage.

\begin{tabular}{lccccc}
\hline m.c. $(\%)$ & \multicolumn{2}{c}{ Duration of prechilling before storage (weeks) } & \multicolumn{2}{c}{ Average } \\
\cline { 2 - 5 } & $\mathrm{X}$ & $\mathrm{X}+2$ & $\mathrm{X}+4$ & $\mathrm{X}+6$ & $\mathrm{GP}$ \\
\hline 28 & $46.0 \mathrm{a}$ & $52.5 \mathrm{a}$ & $60.0 \mathrm{a}$ & $47.5 \mathrm{a}$ & $51.5 \mathrm{~B}$ \\
30 & $71.5 \mathrm{ab}$ & $77.0 \mathrm{a}$ & $77.0 \mathrm{a}$ & $61.0 \mathrm{~b}$ & $71.6 \mathrm{~A}$ \\
32 & $72.0 \mathrm{ab}$ & $80.0 \mathrm{a}$ & $78.0 \mathrm{a}$ & $54.0 \mathrm{~b}$ & $71.0 \mathrm{~A}$ \\
34 & $73.0 \mathrm{a}$ & $69.5 \mathrm{a}$ & $73.0 \mathrm{a}$ & $23.5 \mathrm{~b}$ & $59.8 \mathrm{~B}$ \\
Average GP & $65.6 \mathrm{a}$ & $69.8 \mathrm{a}$ & $72.0 \mathrm{a}$ & $46.5 \mathrm{a}$ & \\
\end{tabular}

m.c.: moisture content. In the same row (small letters) or column (capital letters) values sharing the same letter are not significantly different. For germination, data are given in GP, but statistical comparisons have been operated on the number of germinated seeds per replicate.

Table IV. Prechilling and drying applied before storage. Mean germination time (MGT) AT $3 \% / 20^{\circ} \mathrm{C}$ after 18 months of storage.

\begin{tabular}{|c|c|c|c|c|c|}
\hline \multirow[t]{2}{*}{ m.c. $(\%)$} & \multicolumn{4}{|c|}{ Duration of prechilling before storage (weeks) } & \multirow{2}{*}{$\begin{array}{c}\text { Average } \\
\text { MGT }\end{array}$} \\
\hline & $\mathrm{X}$ & $x+2$ & $X+4$ & $x+6$ & \\
\hline 30 & $16.1 \mathrm{~b}$ & $13 \mathrm{a}$ & $12.8 \mathrm{a}$ & $11.6 \mathrm{a}$ & $13.4 \mathrm{~A}$ \\
\hline 32 & $16.4 \mathrm{~b}$ & $14.3 \mathrm{a}$ & $13.1 \mathrm{a}$ & $12.5 \mathrm{a}$ & 14.1 A \\
\hline 34 & $18.4 \mathrm{c}$ & $14.7 \mathrm{ab}$ & $14.1 \mathrm{a}$ & $15.5 b$ & $15.7 \mathrm{~B}$ \\
\hline
\end{tabular}

m.c.: moisture content. In the same row (small letters) or column (capital letters) values sharing the same letter are not significantly different.

\subsubsection{Results in the nursery}

Results for seedling emergence obtained in the nursery (figure 2) were similar to those obtained in the laboratory (tables III-VI). Even if there were no significant differences in SEP between the six treatments (applied before or after storage), overall the behaviour of seeds stored after being prechilled seemed slightly better than that of seeds classically prechilled just before sowing. However, the rate of seedling emergence was slightly faster with the seed prechilled after storage (MGT $=16.6$ ) than with seed prechilled before storage $(\mathrm{MGT}=17.7)$, probably because they were sown at a higher m.c.

\subsection{The changes in germination of prechilled seeds during storage}

Figure 3 shows all the results obtained in the laboratory during the 3 years of storage. Good stability was obtained at 30 and $32 \%$ m.c. with durations $X$ and $X+2$ weeks with no significant loss of germination after 3 years of storage. However, the best maintenance of GP

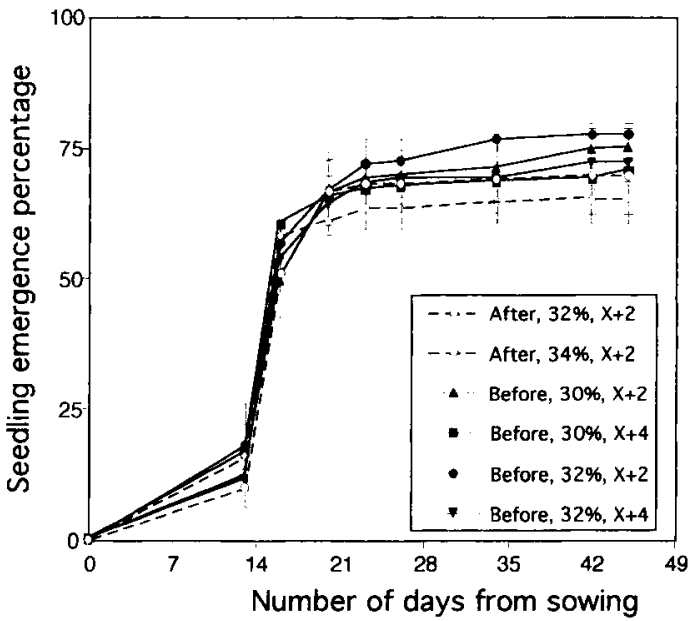

Figure 2. Seedling emergence percentage (SEP) in the nursery after 18 months of storage. Comparison between seeds prechilled before storage (Before) and seeds prechilled after (After) at moisture contents of 30,32 and $34 \%$ and for durations $X+2$ and $X+4$. 
Table V. Prechilling applied after dry storage. Germination percentage (GP) at $3{ }^{\circ} / 20^{\circ} \mathrm{C}$ after 18 months of storage.

\begin{tabular}{|c|c|c|c|c|c|}
\hline \multirow[t]{2}{*}{ m.c. $(\%)$} & \multicolumn{4}{|c|}{ Duration of prechilling after storage (weeks) } & \multirow{2}{*}{$\begin{array}{c}\text { Average } \\
\text { GP }\end{array}$} \\
\hline & $X+2$ & $x+4$ & $x+6$ & $x+11$ & \\
\hline 30 & $60.5 \mathrm{a}$ & $58.5 \mathrm{a}$ & $59.5 a$ & $58.5 \mathrm{a}$ & $59.3 \mathrm{AB}$ \\
\hline 32 & $69.5 \mathrm{a}$ & $64.0 \mathrm{a}$ & $63.0 \mathrm{a}$ & $63.0 \mathrm{a}$ & $64.9 \mathrm{~A}$ \\
\hline 34 & $71.0 \mathrm{a}$ & $67.0 \mathrm{a}$ & $68.5 \mathrm{a}$ & $69.0 \mathrm{a}$ & $68.9 \mathrm{~A}$ \\
\hline Average GP & $67.0 \mathrm{a}$ & $63.2 \mathrm{a}$ & $63.7 \mathrm{a}$ & $63.5 a$ & \\
\hline
\end{tabular}

m.c.: moisture content. In the same row (small letters) or column (capital letters) valucs sharing the same letter are not significantly different. Data are given in GP, but statistical comparisons have been opcrated on the number of germinated seeds per replicate.

Table VI. Prechilling applied after dry storage. Mean germination (MGT) at $3 \% / 20^{\circ} \mathrm{C}$ after 18 months of storage.

\begin{tabular}{lccccc}
\hline m.c. (\%) & \multicolumn{3}{c}{ Duration of prechilling after storage (weeks) } & \multicolumn{2}{c}{ Average } \\
\cline { 2 - 5 } & $\mathrm{X}+2$ & $\mathrm{X}+4$ & $\mathrm{X}+6$ & $\mathrm{X}+11$ & $\mathrm{MGT}$ \\
\hline 30 & $8.1 \mathrm{ab}$ & $9.1 \mathrm{~b}$ & $7.7 \mathrm{a}$ & $7.7 \mathrm{a}$ & $8.2 \mathrm{~B}$ \\
32 & $7.5 \mathrm{ab}$ & $8.6 \mathrm{~b}$ & $7.3 \mathrm{~b}$ & $6.2 \mathrm{a}$ & $7.4 \mathrm{~A}$ \\
34 & $7.2 \mathrm{ab}$ & $7.8 \mathrm{~b}$ & $6.4 \mathrm{a}$ & $6.9 \mathrm{ab}$ & $7.1 \mathrm{~A}$ \\
Average MGT (days) & $7.6 \mathrm{~b}$ & $8.5 \mathrm{c}$ & $7.1 \mathrm{ab}$ & $6.9 \mathrm{a}$ & \\
\end{tabular}

m.c.: moisture content. In the same row (small letters) or column (capital letters) values sharing the same letter are not significantly different.

was obtained with a prechilling performed at $30 \%$ m.c. for $\mathrm{X}+2$ weeks. When the duration was longer than $\mathrm{X}+2$ weeks, there was a large decrease of GP after the 2nd year of storage, which was significant at 32 and $34 \%$ m.c. At $28 \%$ m.c., even though GP was never high, it did not decline.

Poor results were generally obtained for $X+6$ weeks of prechilling and to some extent for $\mathrm{X}+4$ weeks, especially at 32 and $34 \%$ m.c. This decrease was already noticeable after 1 year of storage.

\section{DISCUSSION}

Following the ideas of Suszka $[17,20]$, beechnuts have now been successfullly stored prechilled for up to 30 months [11], 42 months $[12,14]$ and even 6 to 8 years [5, $10,13]$.

Since the 1990s, the drying and storage of prechilled seeds has also been successfully developed for seeds of other hardwood species, particularly Fraxinus excelsior [25] and Prunus avium [14]. In the case of conifers, storage of prechilled seeds has been difficult, particularly when they were redried to a m.c. of $10 \%$ or less $[1,3,4$, 7, 27]. In 1995, Jones [8] succeeded in redrying Picea sitchensis seeds to $7 \%$ without any loss of viability but some dormancy was reinduced during storage. Recently, we have obtained positive results with prechilled Douglas fir seeds stored at $6 \%$ m.c. (Muller, unpublished results); neither re-imposition of dormancy nor loss of viability were observed after 2 years of storage.

In the case of beechnuts, the key is in prechilling at a controlled moisture content which permits the breaking of dormancy without allowing the germination. The proposed prechilling m.c. have varied from one author to another. However, in all cases, the values range between 28 and $32 \%[2,5,12,13,18,20,21,23]$.

In the present study, our first objective was to optimize prechilling conditions before drying and storage. Just after prechilling (table I), the high GPs (around $80 \%$ ) were obtained at m.c. between 30 and $34 \%$ m.c. At $28 \%$ m.c., GP was significantly lower $(64.3 \%)$, which suggests that at this m.c. not all the seeds have had their dormancy broken. Therefore, the prechilling moisture content must not drop below $30 \%$.

To take into account the heterogeneity of the seedlot, the prechilling duration can be varied for different seedlots. For dormancy breaking without further storage, durations ranging from 4 to 20 weeks have been pro- 


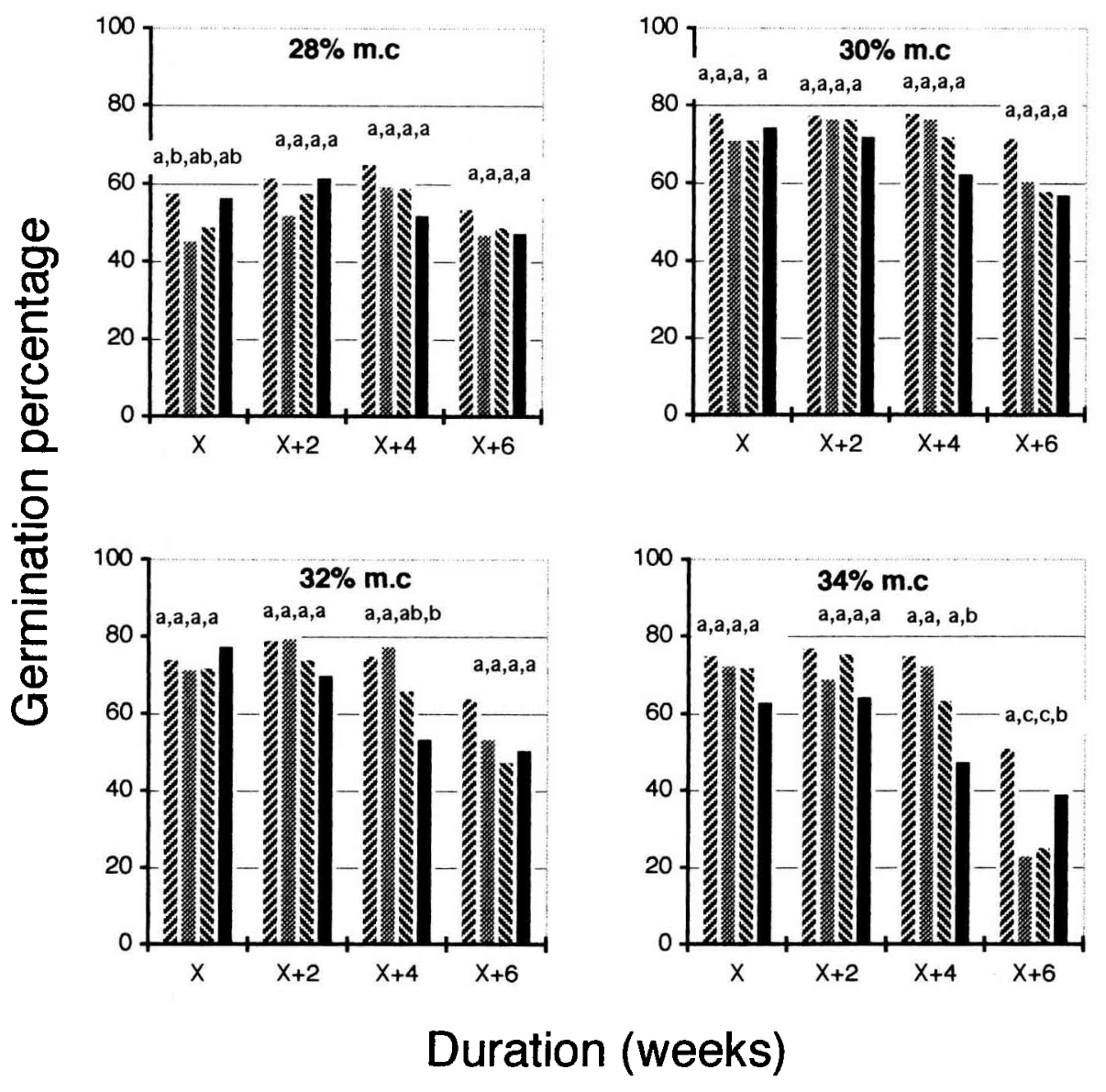

Figure 3. Variation of germination percentage during storage: effect of moisture content (m.c.) and duration of prechilling. Germination percentage obtained at $3 \% 20{ }^{\circ} \mathrm{C}$. Just after drying $(\boldsymbol{\sim})$, after 1 year ( $), 2$ years ( ), 3 years ( $)$ of storage. posed. Recently, Derkx and Joustra [2] reported that a cold prechilling of 16-20 weeks is required to obtain the optimal dormancy breakage in freshly harvested beechnuts. Gille and Nowag [5], advocated 14 weeks for all seedlots. Other authors $[12,18,20]$, however, prefer to adjust the duration of the prechilling to the estimated degree of dormancy of each seedlot. As already mentioned, this estimate refers to an $X$ value (in weeks) [20] where $X$ is, for a given seedlot, the duration necessary to obtain $10 \%$ of germination of viable seeds under conditions of stratification in a wet medium. In our experiments, increased germination was obtained between $\mathrm{X}+2$ and $\mathrm{X}+6$ weeks (table I) with no significant difference in this range of durations if there was no further storage.

When storage is planned, it is necessary to dry the seeds. We have shown here that this drying causes a decrease (table II, figure I) of the GP. However, for the shortest duration $(\mathrm{X})$, which was clearly insufficient for full dormancy breakage, an increase of GP was observed after drying. Similar stimulation of seed germination by reducing water content has also been observed in the mature or immature seeds of many species (see review by Thomsen [24]). It has also been observed in dormant tree seeds, Aesculus hippocastanum [15] and Fagus sylvatica [17]. According to Thomsen [24], drying can replace part of the cold requirement for beechnuts. In her case drying the beechnuts to $8 \%$ m.c. gave the same results as 3 to 4 weeks of cold stratification.

Our experiment confirms that drying after prechilling has the same positive effect on the seeds whose dormancy was incompletely eliminated after $\mathrm{X}$ weeks. In our case, such treatment replaced two weeks of cold and therefore no significant difference was observed between $\mathrm{X}$ and $\mathrm{X}+2$ weeks after drying (table II) as opposed to a significant difference before drying (table $I$ ). On the other hand, seeds with the longest prechilling ( $X+6$ weeks) sig- 
nificantly suffered from drying, especially if it was combined with a high m.c. ( $34 \%)$. In the latter case, a loss of about $40 \% \mathrm{GP}$ is observed. According to Derkx and Joustra [2], it is possible that early germinative events, which start at the end of dormancy breaking, reduce the tolerance to dessication.

After prechilling, the beechnuts were dried at a moderate temperature (around $18-20^{\circ} \mathrm{C}$ ) down to $7-8 \%$ m.c. Prechilled beechnuts seem to be more sensitive to drastic drying (e.g. drying to moisture content around $5 \%$ ) than dormant beechnuts (Muller, unpublished results). However this needs further investigation.

The current experiments demonstrated that beechnuts can be successfully stored in sealed containers at $-7^{\circ} \mathrm{C}$ for at least 3 years (figure 3 ). If they are to be stored in a non-dormant state, the best maintenance of GP was observed after a prechill at $30 \%$ m.c. for $\mathrm{X}+2$ weeks, which confirms previous results $[5,12,13]$.

Another outcome of our experiments concerns the comparison between conditions for dormancy breakage, when the treatment is applied before or after storage. In fact, several possible combinations between prechilling and storage have been proposed for beechnuts [10, 14]: prechilling before storage, during storage [21]. Until now, the same prechill conditions have been proposed for these different cases: $30-32 \%$ m.c. for $X+2$ weeks $[19,22,23]$. In the present experiment, prechilling, whether it was applied before or after storage, led to relatively similar results, in the laboratory (tables $I I I-V I$ ) and in the nursery (figure 2), after 18 months of storage. However, when prechilling was applied after storage (table $V$ and $V I$ ), there was some advantage from increasing the moisture content to $32-34 \%$ m.c., i.e. $2 \%$ higher than when seeds were prechilled before storage (table III and IV).

In conclusion, the ability to dry and store non-dormant seeds has definitely opened new possibilities in the handling and preparation of dormant species. The integration of dormancy release treatments with seed storage for deep dormant hardwood seeds ensures the availability of non-dormant seeds that are able to germinate without any further pretreatment even after long storage. It brings a flexibility to a situation where the constraints (including the necessary variability of the seeds from very diverse trees) are numerous and represents an important advance in the technology of forestry seeds.

Acknowledgements: This work was supported by the European Union through the project AIR2-CT93-1667: 'A multidisciplinary approach to the understanding and efficient handling of seed dormancy in tree species'. The authors are grateful to Simon Hawkins for critical reading of the manuscript

\section{REFERENCES}

[1] Barnett J.P., Germination temperatures for conifer culture of southern pines, Southern J. Appl. For. 3 (1979) 13-14.

[2] Derkx M.P.M., Joustra M.K., Dormancy breaking and short term storage of pretreated Fagus sylvatica seeds, in: Ellis R.H., Black M., Murdoch A.J., Hong T.D. (Eds.), Basic and Applied Aspects of Seed Biology, Proceedings of the Fifth International Workshop on Seeds, Reading, 1995, Kluwer Academic Publishers Dordrecht/Boston/London, 1997, pp. 270-278.

[3] Edwards D.G.W., Storage of prechilled Abies seeds. Proc. IUFRO Int. Symp. Forest Tree Seed Storage, PNFI, Ontario, Canada, 23-27 September 1980, 1980, pp. 195-203.

[4] Edwards D.G.W., Special prechilling techniques for tree seeds, J. Seed Technol. 10 (2) (1986) 151-171.

[5] Gille K., Novag A., Storage of beech seeds, Allg. Forst. Zeitschrift 50 (18) (1995) 960-961.

[6] Gosling PG., Beechnut storage: a review and practical interpretation of the scientific literature, Forestry 64 (1991) $51-59$

[7] Hedderwick GW., Prolonged drying of stratified Douglas fir seeds affects laboratory germination, New Zealand For. Serv., For. Res. Instit. Research Leaflet no. 19, 1968.

[8] Jones SK., Sitka spruce (Picea sitchensis) seed germination in relation to seed development, dormancy and storage, PhD thesis, Department of Agriculture, Earley Gate, Reading, 1995, pp. 62-86.

[9] Kotowski F., Temperature regulation to germination of vegetable seeds, Proc. Am. Soc. Hortic. Sci. 23 (1962) 176-184.

[10] Muller C., Combination of dormancy breaking and storage for tree seed: new strategies for hardwood species, In: Edwards D.G.W. (Ed.), Dormancy and Barriers to Germination, Proc. Intern. Symp. of IUFRO Project Group P2-04-00 (Seed Problems), Victoria, BC, Canada, 1993, pp. 79-85.

[11] Muller C., Bonnet-Masimbert M., Levée de dormance des faines avant leur conservation: résultats préliminaires, Ann. Sci. For. 42 (1985) 385-396.

[12] Muller C., Bonnet-Masimbert M., Breaking dormancy before storage: an improvement to processing of beechnuts (Fagus sylvatica L.), Seed Sci. Technol. 17 (1989) 15-26.

[13] Muller C., Bonnet-Masimbert M., Storage of non-dormant hardwood seeds: new trends, Ann. Sci. For. 46 (Suppl.) (1989) 92s-94s.

[14] Muller C., Bonnet-Masimbert M., Laroppe E., Nouvelles voies dans le traitement des graines dormantes de certains feuillus: Hêtre, Frêne, Merisier, Rev. For. Fr. 42 (1990) 329-345.

[15] Suszka B., Conditions for the breaking of dormancy and germination of the seeds of Aesculus hippocastanum L., Arbor. Kornickie 11 (1966) 203-220.

[16] Suszka B., Dormancy, storage and germination of Fagus sylvatica L., Arbor. Kornickie 11 (1966) 221-240.

[17] Suszka B., Cold storage of after-ripened beech (Fagus sylvatica L.) seeds, Arbor. Kornickie 20 (1975) 299-315. 
[18] Suszka B., Seedling emergence of beech (Fagus sylvatica L.) seed pretreated by chilling without medium at controlled hydrations levels, Arbor. Kornickie 24 (1979) 11-135.

[19] Suszka B., Kluczynska A., Seedling emergence of stored beech (Fagus sylvatica L.) seed prechilled at a controlled hydration level and pregerminated in cold moist conditions, Arbor. Kornickie 21 (1980) 231-255.

[20] Suszka B., Zieta L., Further studies on the germination of beech (Fagus sylvatica L.) seed stored in an already afterripened condition, Arbor. Kornickie 21 (1976) 279-296.

[21] Suszka B., Zieta L., A new presowing treatment for cold stored beech (Fagus sylvatica L.) seed, Arbor. Kornickie 22 (1977) 237-255.

[22] Suszka B., Muller C., Bonnet-Masimbert M., Graines des feuillus forestiers de la récolte au semis, Inra Editions, Paris ISBN 2-7380-0516-0, 1994, pp. 175-211.
[23] Suszka B., Muller C., Bonnet-Masimbert M., Seeds of forest broadleaves: from harvest to sowing, Inra Editions, Paris ISBN 2-7380-0659-0, 1996, pp. 75-211.

[24] Thomsen K.A., The effect of harvest time and drying on dormancy and storability in beechnuts, in: Ellis R.H., Black M., Murdoch A.J., Hong T.D. (Eds.), Basic and Applied Aspects of Seed Biology, Proceedings of the Fifth International Workshop on Seeds, Reading, 1995, Kluwer Academic Publishers Dordrecht/Boston/London, 1997, pp. 45-51.

[25] Tylkowski T., Mediumless stratification and dry storage of after-ripened seeds of Fraxinus excelsior L., Arbor. Kornickie 35 (1990) 143-152.

[26] Vanesse R., Influence du séchage secondaire des graines de Pseudotsuga menziesii (Mirb) Franco sur leur germination à $20{ }^{\circ} \mathrm{C}$, Bull. Rech. Agron. Gembloux 2 (1967) $55 \mathrm{I}-558$. 